\title{
WE LIVE FORWARDS BUT UNDERSTAND BACKWARDS: LING UISTIC PRACTICES AND FUTURE BEHAVIOR ${ }^{1}$
}

BY

HENRY JACKMAN

\begin{abstract}
A bstract: A scriptions of content are sensitive not only to our physical and social environment, but also to unforeseeable developments in the subsequent usage of our terms. The paper argues that the problems that may seem to come from endorsing such 'temporally sensitive' ascriptions either already follow from accepting the socially and historically sensitive ascriptions Burge and $\mathrm{K}$ ripke appeal to, or disappear when the view is developed in detail. If one accepts that one's society's past and current usage contributes to what one's terms mean, there is little reason not to let its future usage to do so as well.
\end{abstract}

\section{Introduction}

$M$ any recent developments in the philosophy of language can be understood in light of G areth Evans' claim that "If a speaker uses a word with the manifest intention to participate in such-and-such a practice, in which the word is used with such-and-such semantic properties, then the word, as used by him, will possess just those semantic properties." ${ }^{2}$ I n particular, various types of 'externalism' can be understood as making explicit our implicit understanding of the linguistic practices we participate in. For instance, (and very roughly) K ripke's work draws on the intuition that these practices extend into the past, Putnam's on the intuition that these 
practices are always located in a given physical environment, and Burge's on the intuition that these practices are shared. ${ }^{3}$ This paper will discuss a further consequence of the fact that, in using a language, we typically understand ourselves as taking part in a shared, temporally extended, and ongoing practice. Specifically, this last feature of our linguistic practices suggests that what we mean by our terms can be affected by 'accidental' developments in their subsequent usage.

W hile some have rejected this purported tie between what we mean and the linguistic practice we take part in, many have accepted that I can, say, refer to Thales by 'Thales' because he stands at the beginning of a historical chain of usage that my present use of the term is a part of, or that what I mean by, say, 'contract' is partially determined by how the term is used in my community. However, once one accepts the admissibility of such 'historical' and 'social' ascriptions, there is little reason not to accept certain 'retrospective' attributions of content that we commonly make. This paper will thus argue for the conditional claim that if our understanding of meaning and content is brought into line with the ascriptional practices appealed to by K ripke, Putnam, and Burge, then there remains little to prevent us from incorporating those ascriptions that make future usage relevant as well. ${ }^{4}$

\section{Two cases $^{5}$}

Our everyday ascriptions of content reflect a sensitivity not only to the structure of a speaker's physical and social environment (including the previous usage of his terms), but also to 'accidental' developments in his terms' usage in the period subsequent to his utterance. For instance, imagine a speaker, Edwin, who is a member of an isolated community (hereafter 'the D ruids') inhabiting an island on which the class of birds and the class of flying things are coextensive. He has a term 'ave' that he applies to these locally coextensive classes, and he has beliefs such as, 'only aves can fly,' and 'all aves are living things,' that are true of the 'aves' on the island. Edwin's (and his fellow D ruids') ave-beliefs will be split in just this way, with as many of them favoring bird as flying thing. A $n$ interpreter may thus initially have difficulty determining precisely what Edwin means by his term. N evertheless, when $E$ dwin first sees planes up in the sky, he unproblematically classifies them as aves, and when he subsequently sees one land, he comes to the immediate realization that not all aves are living things. In spite of the initial unclarity in his usage, Edwin understands himself as having always meant flying thing by 'ave,' and recognizes that a number of those earlier beliefs that he had about aves (such as that they were all living things) were false. It would be entirely natural for Edwin's interpreters to come to this understanding of him as well. 
H owever, had Edwin initially seen planes on the ground, he would have equally unproblematically classified them as non-aves, and if he subsequently saw one take off, he would have come to the immediate realization that not all flying things were aves. In spite of the initial unclarity in his usage, Edwin would have understood himself as having always meant bird by ave, and recognized that a number of those earlier beliefs that he had about aves (such as that only aves could fly) were false. In neither case would E dwin see himself as having changed what he meant by 'ave.' Both Edwin and his peers would see his current usage as following naturally from his previous usage.

There may be no way to tell in advance whether or not Edwin will ultimately include planes within the extension of 'ave,' because the mode in which he first encounters planes may determine the comparative entrenchment of his 'ave'-involving beliefs and attributions. These initial encounters thus determine which of his beliefs will be given up once the conflicts within his use of the term become apparent. ${ }^{6}$ W hen Edwin first saw planes flying high in the sky, his belief that all flying things were aves led him to call the planes 'aves.' Planes were thus already entrenched within what Edwin took to be the extension (hereafter 'the putative extension') of 'ave' when he first saw one land and realized that it was not a living thing. A s a result, upon seeing the first grounded plane, he gave up the belief that all aves are living things, and thus reached a consistent set of beliefs and attributions (hereafter 'an equilibrium') in which 'ave' meant flying thing. On the other hand, had he first seen planes on the ground, his belief that all aves were living things would have entrenched planes within the putative anti-extension of 'ave.' This entrenchment would cause him, upon discovering that planes could fly, to reject the belief that only aves could fly. $\mathrm{H}$ e would thus reach an equilibrium in which 'ave' meant bird rather than flying thing. Even when there is more than one equilibrium available for our terms, certain contexts can make particular patterns of resolution seem so obvious that alternatives are not even considered.

F urthermore, how our utterances are interpreted may be affected not only by our own future behavior, but also by the future behavior of others. F or instance, the term 'G rant's zebra' was introduced around 1820 for a type of zebra native to K enya. A few years later, the term 'Chapman's zebra' was introduced for a morphologically distinct type of zebra found in present-day Zimbabwe. Later still it was discovered that the two types of zebra interbred near the Zambezi river and that, morphologically, one gradually faded into the other. G rant's and Chapman's zebras both turned out to be a races of the species Equus burchilli (one race of which, the quagga, is arguably not a type of zebra at all). ${ }^{7} \mathrm{~W}$ hile the story of ' $G$ rant's zebra' is fairly unremarkable, it suggests an inference parallel to that drawn from $\mathrm{E}$ dwin's use of 'ave.' $\mathrm{N}$ amely, it is merely a historical accident that the term has the extension it does. If the taxonomists had investigated 
the area around the Zambezi river before they hit deepest Zimbabwe, they probably would have 'discovered' that Grant's zebra could be found through most of East A frica, gradually changing into a different subspecies as it drifted south. In such a case, 'G rant's zebra' would have picked out the entire species, not just the race found in K enya. ${ }^{8}$ Such cases suggest that, when we interpret the past use of other speakers (and even ourselves), we help ourselves to subsequent specifications which were not determined by the facts available at or before the time of utterance. (Indeed, the specifications may even take place after the speaker's death.) Treating such ascriptions as correct involves accepting a type of 'temporal externalism' (hereafter 'T-externalism') according to which the future behavior of an individual or his society can affect the content of his thoughts and utterances.

\section{M otivating the $V$ iew: $L$ inguistic Practices}

A sE vans noted, our words are often (correctly) taken to have the semantic properties that the linguistic practices we intend to take part in associate with them. Our conception of our linguistic practice (whether we understand it as shared, continuous with past usage, and so on) determines just what our reliance on that practice commits us to. ${ }^{9}$ Our linguistic practices are not understood as limited to thin temporal slices corresponding to a moment of utterance. $R$ ather, the very idea of a linguistic practice involves some notion of temporal extension. Indeed, the admission of K ripke's intuitions about the relevance of past usage already commits one to a conception of linguistic practices as extending through time. If we allow past usage to be part of the practice we take part in, then (given that we are part of the future's past) future usage will typically be part of the same practice as well. It would be arbitrary to insist that our usage is part of a temporally extended practice that ends with our current utterance. Indeed, one cannot consistently claim that one's practice stops with one's current utterance, and then go on to view one's next utterance as itself the conclusion of a practice that included the prior utterance. When we make an utterance, we often commit ourselves to future refinements in communal usage because these refinements determine just what linguistic practice our usage is (and has always been) a part of.

There may be a number of possible equilibria for an individual's or society's practice of using a term. We can call an equilibrium 'accessible' if it both preserves a sufficient number of entrenched beliefs and applications, and has no competitor that preserves significantly more. ${ }^{10} \mathrm{~N}$ ot all possible equilibria will be accessible; some consistent subsets of the beliefs and applications associated with a term will be incompatible with too many deeply entrenched beliefs and applications to be endorsed by the 
speaker. A term's usage at a time may have a number of equilibria accessible to it. These accessible equilibria set limits upon how much linguistic usage can change within a practice, without changing the meaning of the terms involved. A practice can evolve as its characterization of a term's meaning is made more determinate, but it need not actually be viewed as changing unless it settles on an equilibrium that was not a member of the set originally accessible to it. A s long as the practice remains the same, so does the meaning of the term tied to it.

It is fortunate that we incorporate social and historical usage into the practices we take part in. Otherwise what we mean would often be indeterminate. $M$ uch the same can be said for future usage, since future usage is often required if we are to arrive at a determinate extension for our terms. A n individual's (or even an entire society's) usage can, up to any given time, fail to pick out a determinate extension for a term, and this provides a reason to expand the set of factors relevant to what the term picks out. Given that we actually help ourselves to future specifications when making ascriptions, future usage is an obvious candidate to be included within such an expanded set. The synchronic division of labor is manifested in our confidence that, while we may not know exactly what falls under the extension of a given term, somebody else does. The diachronic division of labor is manifested in our confidence that, even if nobody knows exactly what falls under the extension of a given term, once somebody did, or someday somebody will. ${ }^{11}$ We typically see our predecessors, our successors, and ourselves as part of a continuous process of using, and discovering the correct extension of, the same terms.

A $n$ advantage of non-individualistic accounts of content is that they can accommodate the idea that members of a linguistic community mean the same things by their words. Similarly, it is an advantage of $\mathrm{T}$-externalistic accounts of content that they can understand present and past stages of a linguistic community as talking about the same things. ${ }^{12}$ Indeed, the continuity preserved is not only between past and future stages of our society, but between our past and future selves. ${ }^{13} \mathrm{~T}$ he $\mathrm{T}$-externalist is thus unusually faithful to our assumption that the meanings of our terms stay fairly constant over time.

When what we have said in the past underdetermines what we have committed ourselves to, it seems most plausible to say that our own subsequent utterances can specify the commitments involved in our earlier ones. The assertions one makes in the future can help determine the correctness conditions by which one's entire set of assertions is evaluated. U nless our previous usage clearly commits us to a certain meaning, we are entitled to specify just what we are committed to with our words. ${ }^{14}$ However, once we allow individuals to specify their commitments this way, the acceptance of the so-called 'division of linguistic labor' can result in what someone means by their own terms being dependent upon the future behavior of 
others. F or instance, if Edwin's later usage can determine what he always meant by 'ave,' and there are people who rely upon Edwin for their use of 'ave,' then E dwin's future usage can determine what they al ways referred to by 'ave.' If his neighbor relies upon Edwin's 'ave' expertise, and dies before $E \mathrm{dwin}$ first encounters planes, $\mathrm{E} d$ win's usage after his friend's death could determine what that friend had referred to with the term.

\section{Elaborating the View: $\mathrm{M}$ eanings and $\mathrm{H}$ istories ${ }^{15}$}

T-externalism gives future behavior a significant role in determining what we currently mean. Consequently, it should not be surprising that some of the formal apparatus designed to account for explicitly future-directed statements can also help explicate a T-externalistic semantics. In particular, the use of 'ave' and ' $G$ rant zebra' can be characterized in terms of the following:

1. a moment (' $m$ ') is a spatially complete but instantaneous event: all of nature idealized to a zero temporal thickness;

2. the causal ordering relation, $m_{1} \leq m_{2}$. (This relation is taken to be reflexive, transitive, and anti-symmetrical.);

3. a history (' $h$ ') is a maximal chain of moments;

4. our world. The set of all moments that are connected to this very moment by means of any zigzag combinations of the causal ordering relation or its converse. Every two moments of our world have some common historical ancestor. All branching is forward, never backward. Incompatible moments in our world never have a common upper bound.

A bare moment is not enough for the evaluation of the truth of all of the utterances made at that moment. What one needs is a moment/history pair. The truth-value of many of our utterances, especially those about the future, depends upon how history continues after the moment of utterance, and so such histories must be included within the context of evaluation. The truth-value of a sentence is always relative to a history.

The contribution of the future in determining the truth-value of state ments, either in the future tense or containing temporally loaded expressions such as 'the losing bet' or 'the final battle,' has long been recognized. The T-externalist suggests that the class of these statements will be much larger than initially thought. In particular, the contribution of the future is often needed not only to determine the truth-value of the proposition expressed, but also to determine just what proposition is expressed. For instance, the zebras in Zimbabwe do not have striped feet, but those in $\mathrm{K}$ enya do. As a result, the truth-value of someone's utterance in 1820 of 
"G rant's zebra has striped feet" will vary from history to history. It will be true in those histories where ' $G$ rant's zebra' means Grant's zebra, and false on those where it means Equus burchilli. In such cases, future usage does not make the initial claim uttered true or false. $R$ ather, it makes the utterance the particular claim that it is. What makes the claim true (in our history) is still the fact that Grant's zebras have striped feet. F uture usage only contributes to such utterances' truth-value by determining their content.

Of course, some terms and sentences seem to have their meanings and truth-values independently of what may happen in the future. A ssertions that have their truth-value established at a moment, independently of what happens afterwards, can be described in terms of 'settled truth.' Roughly, an assertion is settled true at a moment if it is true in every history passing through that moment. In much the same way, a term's extension can be said to be 'settled' at a moment if the term has the same extension in every history passing through that moment. ${ }^{16}$ The meanings of many of our terms may be 'settled' in just this fashion, just as it may be settled that some of our terms have indeterminate extensions.

Since it takes interpretations to be relative to histories that include both past and future usage, just what consequences T-externalism has for our understanding of meaning will depend partially upon how we understand the future. A determinist, for instance, will understand the passage of time as consisting of a single history $\left(h_{1}\right)$ from the past, through the moment of utterance, and into the future. This history may be represented as follows:

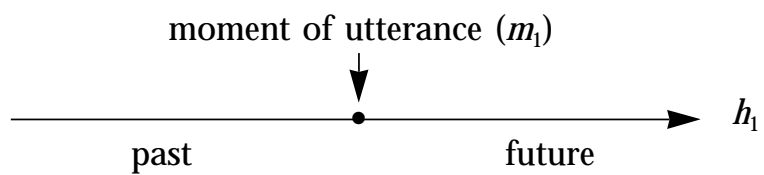

If there is only one possible history, then all truths are settled truths. Consequently, if determinism is true, then it would have always been settled that, say, the zebra enthusiasts would hit deepest Zimbabwe before the Zambezi river, and thus always settled that the term ' $G$ rant's zebra' would be applied exclusively to the zebras in K enya. The future would contain a set of settled facts which, while epistemically inaccessible to us at present, remain settled facts nonetheless. A ccepting that future events contribute to the current meanings of our terms would thus not prevent us from insisting that there are al ways settled facts about what we mean. ${ }^{17}$ On the other hand, if the future is 'open,' then, when 'G rant's zebra' is introduced in 1820, there will be no settled facts about how usage will develop, and thus about which equilibrium will be reached for the term. A T-externalist who took the future to be open would have to describe the G rant's Zebra case as follows: 


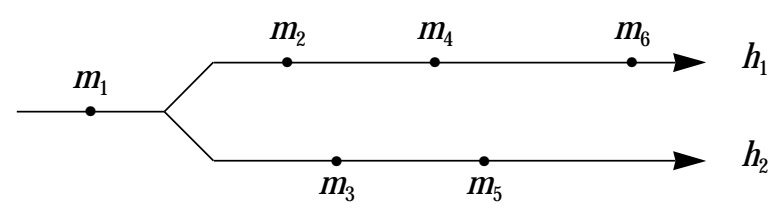

Treating $m_{1}$ as the initial use of the term, there are, say, two possible histories, $h_{1}$ and $h_{2}$, in which the use of the term develops in different ways. In our actual history, $h_{1}$, the term 'C hapman's zebra' was introduced at $m_{2}$, the interbreeding discovered at $m_{4}$, and we are discussing Grant's utterance at $m_{6}$. In the alternative unactualized history, $h_{2}$, the gradual shift at the Zambezi was discovered at $m_{3}$ while the Zimbabwean zebras were found at $m_{5}$. On $h_{2}$, 'G rant's zebra' denotes all of Equus burchilli, while on $h_{1}$ it denotes Grant's zebra.

$\mathrm{T}$-externalism with the open future thus leaves it at $\mathrm{m}_{1}$ not only epistemically but also metaphysically unsettled what 'G rant's zebra' means. $\mathrm{H}$ owever, this seems irrelevant to our current interpretation of 1820 utterances containing 'G rant's zebra.' It is now settled that the term had one history of development rather than any other. While it may be the case that, in 1820, it was not settled that this history would become the actual one, relative to this history, $h_{1}$, the term always meant Grant's zebra. (It is now (that is, at $m_{6}$ ) settled that the term meant Grant's zebra at $m_{1}$, though it was not settled at $m_{1}$ that it meant $G$ rant's zebra.) At $m_{1}$ the full context of evaluation was not yet in place. We would look back on G rant's future tensed utterance of, "I will never be discussed in a philosophy paper," and say that it was false, even though, at the time of utterance, it was not settled false. In an analogous fashion, we can look back at his utterances involving ' $G$ rant's zebra' and treat them as referring to Grant's zebra, even though, at the time of utterance, that extension was not yet settled.

\section{0 bjections and $R$ eplies $^{18}$}

The T-externalist must, of course, deal with the fact there is a strong inclination to think that, say, what someone meant by ' $G$ rant's zebra' in 1820 cannot depend upon what other naturalists did in 1823. In such cases, many, if not most, people are willing to say that the ascriptions supporting $\mathrm{T}$-externalism are misleading. $\mathrm{N}$ evertheless, can this reaction be justified? This section will consider some of the purported reasons that I have heard given for rejecting $T$-externalism, and argue that, once one accepts the types of ascriptions $\mathrm{K}$ ripke, Putnam and Burge appeal to, few, if any, of these purported reasons stand up to scrutiny. 
O bjection: By allowing future events to determine the content of what was thought and said in the past, the T-externalist seems committed to the existence of backwards causation.

R eply: While T-external ism allows future events to contribute to what we meant in the past, the type of contribution involved is not causal. A ccording to the $T$-externalist, the fact that the practice within which a given word is used extends through time allows future usage to help constitute the very practice that the speaker was taking part in at the moment of utterance. ${ }^{19}$ The speaker's utterance is understood in terms of a characterization of the practice that may not have been available at the moment of utterance, but the characterization remains correct nevertheless. ${ }^{20}$ Semantic properties like truth and meaning are history relative, but their dependence on subsequent history is not causal. T-externalistic characterizations no more involve backwards causation than does the truth of my 1995 claim that Clinton would be re-elected in 1996. ${ }^{21}$

$O$ bjection: If $\mathrm{T}$-externalism does not understand the relation between present contents and future usage as a causal one, this itself presents a problem for the view. Externalist theories typically exploit precisely this causal connection between meaning and the 'external' factors that are meant to affect it. If future usage has no causal effect upon present utterances, then it should not affect their content.

Reply: While it may not cause current usage, future usage is, nevertheless, causally connected to it, and this connection is what really matters. Objects and events can be characterized both in terms of their causes (J ohn's sunburn) and their effects (J ohn's fatal jump). W hile future usage does not causally affect our present utterances, it can help determine the relevant characterization of the past usage which does causally affect our utterances. One's usage is causally affected by the practice it is embedded in, and future usage is partially constitutive of what this practice is. Indeed, if one were to take an extremely narrow view of what caused one's usage (the experienced usage of the language users one has had contact with) one would rule out the relevance of much past and social usage as well.

Objection: What one means cannot extend beyond what one could communicate, so information that is unavailable to one's interpreters cannot be relevant to what one means. F uture usage is unavailable to one's interpreters, so it cannot contribute to meaning.

Reply: First of all, there is a sense of 'communicate' in which what was communicated at a time is also determined by future usage. A fter all, if (before seeing any planes) Edwin tells a friend that he has seen over a thousand aves, then that friend can come to believe that Edwin has seen over a thousand aves. A ccording to the T-externalist, the content of both Edwin's utterance and his friend's belief will be determined by future usage, and so it is not much of a stretch to claim that what Edwin communicated by his utterance was so determined as well. 
The objection thus rests on a particularly restrictive notion of meaning and communication by which both are limited to what could be determined by a contemporaneous interpreter ${ }^{22}$ There is, however, little reason to place such restrictions upon what can contribute to meaning, since doing so would exclude important features of the society's past usage as well. Such a restriction would thus rule out much of the name-using practice that $\mathrm{K}$ ripke describes. ${ }^{23} \mathrm{C}$ onsequently, if one accepts such name-using practices, the inability of a contemporaneous interpreter to determine what a person means should be taken to show that all of the semantically relevant facts need not be available at the time of utterance.

One might, of course, try to allow past and present, but not future, usage to contribute to what we mean. $\mathrm{N}$ evertheless, one should have some principled reason for doing so. While principled reasons of a quasi-internalist sort could be given for ruling out both past and future usage, it is much less clear how one could justify ruling out one without the other. One might try to argue that, if the future is open, facts about future usage are not even in principle available to the interpreter ${ }^{24} \mathrm{H}$ owever, when we now interpret, say, G rant's original utterance, it is patently false that we do not have access to his terms' subsequent usage. What information is available to interpreters depends upon the temporal position one takes them to be interpreting from. The claim that what we mean must in principle be available to an interpreter loses most of its plausibility if accompanied by ad hoc restrictions upon the interpreter's evidential base. As long as one allows the evidential base to includes future usage, T-externalism is perfectly compatible with the requirement that what a speaker means by his terms be available to an interpreter.

O bjection: We do not know how future usage will develop, so if such usage contributes to what we presently mean, then we do not know the content of our own thoughts and utterances.

Reply: Given that we are authoritative about neither the world's physical structure nor the usage of our community (especially its past usage), $\mathrm{T}$-externalistic ascriptions no more threaten self-knowledge than do the ascriptions that K ripke, Putnam, and Burge appeal to. Selfknowledge creates no problems that are unique to $\mathrm{T}$-externalism, and the strategies for reconciling self-knowledge with other types of externalism, to the extent that they work, will do so for T-externalism as well. ${ }^{25}$ The relevant conception of self-knowledge is tied to notions like introspection, not to our ability to, say, go look up a definition in a dictionary. The difference between the types of inaccessibility involved is thus not one that makes a difference for self-knowledge. A s a result, a desire to preserve self-knowledge gives no one accepting these other forms of externalism any reason to reject $\mathrm{T}$-externalism.

Objection: By allowing future use to determine the contents of our thoughts, T-externalism prevents us from making sense of the fact that 
our attitudes explain our behavior. A II the facts having to do with whatever causally affects our behavior must be settled before that behavior occurs, so if $\mathrm{T}$-externalism entails that the contents of our thoughts are not settled at the time of our action, then it seems to entail that our thoughts to do not causally affect our behavior.

Reply: Once again, if T-externalism spoils the role of attitudes in behavioral explanations, then they were spoilt already by the practices $\mathrm{K}$ ripke, Putnam, and Burge describe. As a result, if one accepts, say, Burge's thesis about the social character of meaning, then problems with behavioral explanation will give one no reason to treat the T-externalistic practice as mistaken. Whatever solution allows one to incorporate social contents into behavioral explanations should work for T-externalistic contents as well. F urthermore, $\mathrm{T}$-externalistic ascriptions allow one to characterize the beliefs that cause behavior in a way that rationalizes speaker's behavior when faced with novel phenomena. We can explain why, say, Edwin calls the planes he initially sees in the sky 'aves' by the fact that he means flying thing by 'ave.' By preserving the 'internal connection' between content and future applications, the $T$-externalist can thus understand the speaker's behavior in novel situations as being in accordance with what he means by his terms.

Objection: By allowing future usage to determine what we mean, T-externalism allows future linguistic developments that we would intuitively take to be departures from what we mean to determine what we 'really' meant all along. There are, after all, clear cases where future developments in a term's usage should not be retroactively applied to the past. F or instance, the term 'girl' was once applied to both girls and boys, but one should not have to say that the fact that we now apply the term to just girls entails that previous applications of the term to boys were mistaken.

Reply: It should initially be noted that we see structurally similar problems with the relevance of past usage. ${ }^{26} \mathrm{~J}$ ust as we want to say that what we now mean is dependent upon our past usage, but leave room for the possibility that we occasionally break free from it, we want to say that what we mean can depend upon our future usage, but leave room for the possibility of its breaking loose from us. In any case, as stressed in section 3 , in order to be read back retroactively, future usage must develop within the range of equilibria that current usage has accessible to it. This severely constrains the types of linguistic development that can be read back into current usage. If the changes in usage move to an equilibrium that was not originally accessible, then there will be a change in meaning (as in the case of 'girl'). On the other hand, if the change in usage can be understood as a move towards one of the originally accessible equilibria, there need be no change in meaning (as in E dwin's use of 'ave').

O bjection: If a community wereto split, with each sub-community developing accessible but incompatible equilibria from the original community's 
usage, then we would apparently have to attribute both of the incompatible meanings to the original community's utterances.

R eply: Our entitlement to read our own developments back into past usage comes from our predecessors and ourselves being part of a single, developing linguistic practice. Because of this, one can account for such cases by insisting that linguistic practices, like much else, do not preserve their identity through splits. The fact that, when such splits occur, the existence of a rival community undermines each community's entitlement to say what their predecessors meant does not entail that such entitlement is not present when no splitting occurs. ${ }^{27} \mathrm{~A} n$ actual split undermines any identity between past and future, but the mere possibility of a split need not do so.

Objection: T-externalism still entails at least that, when such splits occur, nothing determinate is originally meant by the terms affected.

R eply: This objection can be taken in stride. There are, after all, structurally similar cases within the synchronic social picture and causal/historical accounts of proper names. That a community could split is no more a problem for the T-externalist than the possibility that a speaker's use of a name might be historically connected to two people is a problem for $\mathrm{K}$ ripke, or the possibility that a speaker might unknowingly be part of two linguistically divergent sub-communities is a problem for Burge. ${ }^{28}$ These possibilities are not counterexamples to the accounts in question. $R$ ather, they just suggest that, in some special cases, the accounts entail that nothing determinate will be meant by a term. This would be a problem if our intuitions suggested that something determinate was meant in these cases, but our intuitions tend to agree with the predictions of the accounts.

$O$ bjection: If the D ruids use of 'ave' died out before they encountered planes, the meaning of the term would remain indeterminate between flying thing and bird.

R eply: One should (once again) simply admit that, in such a case, the meaning of 'ave' would be indeterminate. A fter all, the suggestion that what $E$ dwin meant by "ave" would remain indeterminate if the 'ave'-using practice died out before planes were encountered should match our pretheoretical intuitions about such cases. Incorporating the community's future linguistic development can only add to the determinateness of the contents in question, so any scenario in which contents are indeterminate for the T-externalist will also be one in which they are indeterminate for more temporally bound versions of externalism. The T-externalist framework may make this type of indeterminacy more visible, but it can hardly be blamed for its existence.

Objection: T-externalism seems to tie our meaning anything determinate by our words to our linguistic practice's having a non-branching future, but the determinacy of what we mean frequently seems independent of future usage. 
Reply: The meanings of many, if not most, of our terms may be independent of how things turn out in the future. ${ }^{29} \mathrm{H}$ owever, this would only show that there remains just one equilibrium accessible for our use of each of these terms. A s explained in section 4, a term's extension can be 'settled' at a moment if the term has the same extension in every history passing through that moment. The meanings of many of our terms (those for which there is a single accessible equilibrium) may be settled in this fashion. F or instance, by 1750 , our 'gold'-using practice may have evolved enough to make alternate interpretations of the term inaccessible. The D ruids did not, by hypothesis, have such a fully-developed linguistic practice in place governing their use of 'ave.'

O bjection: Suppose that Edwin sees his first planes in 1998, and that his use of 'ave' that year made it the case that he meant bird by 'ave.' The $\mathrm{T}$-externalist seems committed to saying that his usage also made it the case that he always meant bird by 'ave.' H owever, if Edwin always meant bird by 'ave,' then he meant bird by 'ave' in 1987, and so by the time he had seen his first plane, he must have meant bird by 'ave' for over ten years. But how could what Edwin did in 1998 make it the case that he meant bird by 'ave' if he had already meant bird by 'ave' for over a decade? ${ }^{30}$

Reply: Such apparent paradoxes can be attributed to the comparatively course-grained character of the phrase, "make it the case that." It does seem paradoxical to claim that one can make something the case if it already is the case. Such paradoxes disappear, however, if we adopt the finer grained framework outlined in section 4, and describe E dwin's usage in 1998 as settling it that he meant bird by 'ave,' rather than making it the case that he did. If, in 1998, Edwin only settled it that he meant bird by 'ave,' then it could still be the case that he meant bird by 'ave' in 1987. It just could not have been settled that he did. There must have been possible, but not actual, histories in which Edwin did not mean bird running through Edwin's 1987 usage, while no such possible histories could be connected to his 1998 usage.

Objection: The T-externalist's semantics presupposes an incoherent notion of evaluation. The T-externalist claims that (given an open future), in 1820 , the reference of ' $G$ rant's zebra' was unsettled, while the reference of 'Grant's zebra' is now settled as Grant's zebra. But the T-externalist also wishes to claim that our present interpretation of 1820 utterances containing 'Grant's zebra' should treat it as meaning Grant's zebra. However, since the reference of ' $G$ rant's zebra' in 1820 was, as the $\mathrm{T}$-externalist admits, unsettled, the $\mathrm{T}$-externalist seems committed to the incoherent claim that the reference of ' $G$ rant's zebra' considered as uttered in 1820 is both Grant's zebra and unsettled.

Reply: This objection involves treating a term's semantic value being unsettled as itself a type of semantic value. H owever, classifying a term's reference as 'unsettled' is not to assign to it a special sort of semantic 
value. $R$ ather, it is stating that all of the factors required for the term's evaluation are not yet in place. If one were only aware of the facts up until 1820, one could treat the reference of 'G rant's zebra' as unsettled, and by 1840 one could treat it as referring to Grant's zebra. N evertheless, this does not involve a reinterpretation of the term. Claiming that the reference of a term is unsettled is not to provide an interpretation for it, but precisely to admit that one does not have access to what is required to interpret it properly. ${ }^{31}$ There is nothing incoherent in saying that, in 1820 , the reference of ' $G$ rants zebra' was Grant's zebra even if it was not settled that it was. What a term means at a moment is always relative to a particular history, but the question of whether or not its reference is settled at a moment is a function of all of the histories that flow through that moment. Consequently, saying that 'Grant's zebra' referred to Grant's zebra in 1820 in no way requires suggesting that its reference was settled in 1820.

O bjection: One does not need T-externalism to account for cases like Edwin's because there already exists temporally bound semantic theories that can account for them. Indeed, when Wilson first presented his 'D ruids', he suggests that their initial use of 'ave' should be analyzed in terms of something like $F$ ield's notion of partial reference. ${ }^{32} \mathrm{~A}$ ccording to the partial reference theorist, if, at a given time, Edwin's language (call it D) equally supports two rival interpretations, $I_{1}$ and $I_{2}$, that treat his term 'ave' as referring to birds and flying things respectively, then 'ave' partially denotes birds, and partially denotes flying things. The interpretations $I_{1}$ and $I_{2}$ both partially accord with the semantics of $D$, since they both assign to the words in $D$ entities that the terms in $D$ partially denote. Sentences in $D$ can then be understood as true (or false) if they are true (or false) relative to every interpretation that partially accords with $D$. Sentences in $D$ that have different truth-values relative to different interpretations that partially accord with $D$ are neither true nor false. On such an account, Edwin's initial use of the sentence "Some aves are tasty" would be true, since it would be true on both $I_{1}$ and $I_{2}$. On the other hand, his sentence "A ves are found only on this island" would be false, since it is false on both interpretations. Finally, his sentence "A II aves lay eggs" would lack a truth-value, since it is true on $I_{1}$, and false on $I_{2}$. When Edwin finally encounters planes, the meaning of his term will change so that it fully denotes just one of either birds or flying things.

R eply: Since we naturally presuppose that our currant usage determines a single meaning for our terms, any account of what our terms mean when there are multiple equilibria available to them may seem unintuitive in at least some respects. ${ }^{33}$ Consequently, there may be no way to give conclusive reasons for preferring either a T-externalistic or a partial reference semantics over the other. Indeed, such a choice may be difficult precisely because semantic terms like 'meaning' and 'content' are themselves terms 
for which we may not have found a settled interpretation. ${ }^{34}$ Theorists who assign different weights to their general presuppositions about meaning and content may simply have incommensurable views about how meaning should be understood. ${ }^{35} \mathrm{~W}$ hen disputes occur between semantic theorists with such disparate interests, there may be no more reason to think that one of the two must be confused about the nature of meaning than there is to think that either doctors or lawyers must be confused about the nature of narcotics simply because their different interests lead them to assign slightly different extensions to the term. ${ }^{36}$

$\mathrm{N}$ evertheless, if one has already accepted the K ripke, Putnam, and Burge ascriptions, it is unclear whether there would remain any good motives for adopting a partial-reference account. One would like some motive for doing so, since the partial reference theorist will be faced with a comparative lack of both determinacy and continuity of meaning over time. Some partial reference theorists may be able to provide a set of requirements for an adequate semantic theory that would favor partial reference over T-externalism, but those requirements would probably not be satisfied by any account that accepted, say, the contribution of social usage. F or instance, there might be motives for identifying what one currently means directly with how one is currently disposed to use one's terms. Such motives would favor a partial reference account over T-externalism. N evertheless, whatever motives these might be, they will not be available to someone who accepts, say, the contribution of one's society's past and current usage to what one means. Consequently, even if there were no compelling reason for everyone to prefer the $\mathrm{T}$-externalistic account over the partial reference one, there may still be good grounds for adopting the $\mathrm{T}$-externalistic account if one has already accepted some form of the $\mathrm{K}$ ripke and Burge practices.

F urthermore, T-externalism provides one's semantics with a type of fineness of grain absent in its temporally bound competitors. In particular, $T$-externalism allows for a distinction between what we mean being 'indeterminate' and its being 'unsettled.' A term with an unsettled extension could still have a determinate extension in every history, while a term with an indeterminate extension cannot have a determinate extension in any history. The added fineness of grain allows the $T$-externalist to give a semantics for those cases where a partial reference account seems plausible that is structurally very similar to that proposed by Field. ${ }^{37} \mathrm{In}$ particular, in precisely those cases where partial reference accounts will be most appealing (when the practice splits into two, dies off, or has no equilibria accessible to it, and so on), the T-externalist will treat the term's meaning as settled indeterminate. The T-externalist is then free to give a partial reference semantics for those cases, since if a term's meaning is 'settled indeterminate' then no future usage can make it determinate. The sentences that come out as true or false on Field's model would have the 
same values on such $\mathrm{T}$-externalistic theories. For those sentences that involve words whose extension is settled indeterminate, the T-externalist semantics could also mirror the partial reference one. It is only some of the sentences that the partial reference theorists take to have no truthvalue that the $T$-externalist need consider to be settled in the future. Because of this, while various examples can be given for which partial reference accounts seem very plausible, ${ }^{38}$ the $T$-externalist can absorb such examples into his account. On the other hand, while T-externalistic semantics can incorporate most of the mechanisms associated with Field's account, the converse is not the case. The partial reference theorist must treat as having an indeterminate extension not only those cases that the T-externalist treats as settled indeterminate, but also all of those cases that the T-externalist treats as unsettled. This is unfortunate for the partial reference theorist, since a speaker's usage of a term can fail to point to a single interpretation for at least two reasons. F irst, the speaker's usage can be prompted by a source of information that can be conceptualized in two different ways. Both the 'Grant's zebra' and 'ave' cases are like this. Second, the speaker could be 'ontologically confused,' with his usage unknowingly prompted by two independent sources of information. ${ }^{39} \mathrm{~T}$ his sort of underdetermination arises when, say, a speaker mistakenly uses a single name for a pair of twins, each of whom encounters the speaker equally often (though never together). ${ }^{40}$ It would be preferable to give underdetermination a semantic treatment that is distinct from ontological confusion. The T-externalist is able to do this by describing someone's usage at a time as falling into one of four classes, (1) settled with an determinate meaning (Edwin's final use of 'ave'), (2) settled with an indeterminate meaning (ontological confusion), (3) unsettled but with a determinate meaning (Edwin's initial use of 'ave'), and (4) unsettled and with an indeterminate meaning (cases where the practice splits or dies off before it can settle on something determinate). The partial reference theorist, on the other hand, must treat the last three of these cases in the same manner. Ontological confusion and underdetermination (whether it is subsequently resolved or not) are both treated as leading to a type of indeterminacy and receive the same semantic treatment.

F inally, even if there ultimately were no fact of the matter as to whether $\mathrm{T}$-externalistic or partial reference accounts of content should be preferred, it is clear that latter have been more fully explored. It remains to be seen whether $\mathrm{T}$-externalism ultimately creates more problems than it solves, but it may turn out to be conceptually fruitful. Claims that seem unintuitive within a temporally bound framework may lose much of their paradoxical character once future usage is brought into play, ${ }^{41}$ and intuitions which we have al ready accepted may find explanations that are potentially more plausible than those offered thus far..$^{42}$ Consequently, methodological pluralism encourages giving the view a hearing in spite of its at times unintuitive character. 


\section{Conclusion}

Everyday ascriptions of content reflect a sensitivity not only to our physical and social environment, but also to unforeseeable developments in the subsequent usage of our terms. Such 'temporally sensitive' ascriptions are the result of the fact that, when using a language, we understand ourselves as taking part in a shared, temporally extended practice. M ost of the potential problems that come from endorsing such temporally sensitive ascriptions al ready follow from accepting the socially and historically sensitive ascriptions Burge and K ripke appeal to, and there is good reason to think that the remaining problems may disappear when the view is developed in further detail. Consequently, if one is inclined to allow one's society's past and current usage to contribute to what one means by one's terms, then there is no reason not to allow its future usage to do so as well.

D epartment of Philosophy

U niversity of Toledo

\section{NOTES}

${ }^{1}$ I thank Robert Brandom, Joe Camp, James Conant, Richard Gale, M itch Green, $M$ ark M cCullagh, John M CD owell, M adeline M untersbjorn, Ram N eta, Lionel Shapiro, and $M$ ark Wilson for their comments on earlier versions of this paper, and the Canada Council for their generous support.

2 See Evans, 1982, p. 387.

${ }^{3}$ See K ripke, 1972; Putnam, 1975; Burge, 1979.

${ }^{4}$ The intuitions that $\mathrm{K}$ ripke, Putnam, and Burge appeal to are widely shared, and they will not be defended here. They are, however, defended in some detail in Jackman (1996).

${ }^{5}$ These examples are adapted from W ilson (1982). W ilson discusses a number of other such cases, and argues that they occur "in virtually every case of enlargement of our world view through scientific progress" (Wilson, 1982, p. 572).

${ }^{6}$ In this respect, linguistic development is much like case law. (See, for instance, D workin, 1977.)

7 The folk classification 'zebra' does not seem to map on to any well-defined biological kind (G ould, 1983).

${ }^{8} \mathrm{~A}$ nd, indeed, this might have affected the extension of 'zebra' itself, by making it seem more natural to include the quagga under this term.

${ }^{9}$ This is discussed in greater detail in Jackman 1996 and 1998a.

${ }_{10}$ This sketch is, admittedly, a little impressionistic, and an account of the relation between meaning and accessible equilibria is presented in more detail in Jackman (1996).

${ }^{11}$ See Putnam, 1975.

${ }^{12}$ F or a discussion of how interpretations should preserve such continuity of meaning, see K oethe (1982; 1992).

${ }^{13}$ The T-externalist thus allows for more continuity between our past, present and future psychological states. If one is inclined to think of personal identity in terms of psychological continuity, then the $T$-externalist is much friendlier to the thought that we preserve our identity over time. 
${ }^{14}$ F or a fuller discussion of this, see Jackman (1996, 1998a). It should be noted that, while the acceptability of the Burge ascriptions is taken for granted in this paper, one can accept that our future usage can determine what we currently mean, without accepting that our social context affects what we mean in a similar fashion. For instance, the ascriptions that tied what Edwin meant to his future usage could be accepted by someone who did not allow social usage to affect what an individual meant.

${ }^{15}$ The framework used here draws heavily upon the Prior/Thomason tense logics (Prior, 1967; Thomason, 1984), particularly as presented in Belnap and Green (1994). M y use of the Belnap and $G$ reen framework should imply neither that I endorse their rejection of determinism, nor that they accept anything like T-externalism. Indeed, they take an assertion's content to be independent of what happens after it (Belnap and G reen, 1994, p. 382).

${ }^{16} \mathrm{Or}$ at least those futures where the term's usage stays within the range of accessible equilibria. (This topic is discussed further in section 5.) It should also be noted that, even if the interpretation of a speaker's words may not be settled at a particular moment, the truth-value of his utterance may be. Even when what was meant by 'Grant's zebra' was unsettled, an utterance of "G rant's Zebra has stripes" would have been settled true, since it would be true on either candidate interpretation.

${ }^{17} M$ uch the same can be said if one accepts the view that, while there are a number of ways in which the future could possibly develop, there is still a fact of the matter as to what will happen. This version of the future and its consequences for T-externalism is discussed in J ackman (1996).

${ }_{18} \mathrm{M}$ any of these are discussed in greater detail in J ackman (1996).

${ }_{19}$ Brandom (1989) argues that $\mathrm{H}$ egel defends a similar view according to which the contents of our initial intentions are determined by the actions that they subsequently result in.

${ }^{20}$ Such worries about backwards causation may bear some resemblance to those arising from A ristotle's discussion of "posthumous harm" (A ristotle, 1985, 1101). In much the same way, the claim that we are subject to posthumous harm should not be understood in causal terms. R ather, it seems better understood in terms of future events making available true descriptions of our life that allow it to be recognized as less choiceworthy.

${ }^{21}$ In much the same way, if John buys a lottery ticket and has his number drawn five days later, one need not endorse backwards causation to describe his past self as buying the winning ticket. A ctions can be described in terms of their effects without suggesting any backwards causation. Describing a particular speech or mental act partially in terms of events which take place after its occurrence is no more mysterious.

${ }^{22}$ Something like this understanding of meaning and communication might be what leads Wilson not to draw T-externalistic conclusions from his 'ave' and ' $G$ rant's zebra' scenarios. Wilson takes it to be a "rough adequacy condition" on any theory of meaning that, "The evidence for assignment of an extension to a predicate should be limited to such linguistic behavior as can be reasonably extrapolated from the community's contemporaneous practice" (Wilson, 1982, p. 553).

${ }^{23}$ K ripke, 1972.

${ }^{24}$ Though someone coming out of a verificationist tradition (especially of the positivist sort) might reverse this claim and take themselves to have good reason for allowing the contribution of the future but not that of the past. F uture usage is, after all, in principle, available to anyone who waits, while, barring the possibility of time travel, there may be no way for our interpreters to become acquainted with crucial aspects of past usage. As a result, future usage may be better off than past usage when we consider in principle availability to interpreters. (For a discussion of positivists' asymmetric treatment of the future and the past, see M isak, 1995, p. 71.)

${ }^{25}$ F or examples of such strategies, see D avidson, 1987; Burge, 1988; and J ackman, 1996.

${ }^{26}$ See, for instance, the discussion of 'M adagascar' in Evans, 1973. 
${ }^{27} \mathrm{~A} n$ analogous point is frequently made with respect to personal identity: The fact that, if I were to split, I could not be identified with either of my successors, does not, in itself, entail that I cannot be identified with my 'future self' when I do not split.

${ }^{28}$ For examples of such cases, see Evans' discussion of 'N apoleon' (Evans, 1973), and Stich's discussion of the British and A merican use of 'chicory' and 'endive' (Stich, 1983).

${ }^{29}$ Though it should be noted that a term with an unsettled extension rarely seems so to its user.

${ }^{30}$ This problem is similar to one associated with the idea that courts can fill in 'gaps' in the law ex post facto.

${ }^{31}$ In much the same way, while a prediction about the future may eventually go from being unsettled to having a settled truth-value, this is not an instance of its truth-value changing. Characterizing the truth-value of the prediction as unsettled is precisely to admit that no sort of truth-value can presently be assigned to it.

${ }^{32}$ See Field, 1973; 1974. While Field's account will be the focus of this discussion, most of what is said can be carried over to other temporally bound accounts such as, say, those explaining Edwin's utterances in terms of degrees of truth.

${ }^{33}$ We see a similar phenomenon with cases of splitting in discussions of personal identity: Our conceptual apparatus evolved under the assumption that there will be no splits, and no application of that apparatus seems entirely satisfactory when describing the splitting cases.

${ }^{34}$ Indeed, there are many who believe that there cannot be a single settled interpretation for these terms. If deeply entrenched aspects of our use of these semantic terms can be neither given up nor reconciled, there will be a temptation to split the term into two terms for which separate equilibria can be reached. Those who think that we must distinguish between 'narrow' and 'wide' content are effectively accepting such a view.

${ }^{35}$ A s a result, different interpreters, both fully aware of all the physical facts, might still legitimately disagree about how to interpret a given speaker. Quine argued that translation is indeterminate because all the relevant evidence underdetermines the correct interpretations of a speaker's words (Quine, 1960), but translation may (also) be indeterminate because what counts as the relevant evidence is itself indeterminate. In this case, for instance, interpreters may disagree over the relevance of future behavior.

${ }^{36}$ One could also cite physicists versus chemists on what counts as a 'molecule', nutritionists versus botanists what on counts as a 'vegetable', and so on.

${ }^{37} \mathrm{Or}$, if one prefers accounts that rely on, say, degrees of truth to Field's account, one can build such mechanisms into one's T-externalistic semantics as well.

${ }^{38}$ Such as N ewton's use of 'mass' (the example F ield himself uses), which the T-externalist can understand as a type of splitting case.

${ }^{39} \mathrm{~F}$ or a discussion of semantics and ontological confusion, see Camp, 1987.

${ }^{40}$ While semantic underdetermination should be understood as occurring when two or more rival semantic theories can both be compatible with all the available semantic evidence, cases of ontological confusion clearly are not instances of this. It is not that both theories (i.e.: 'Peter' refers to twin \#1 and 'Peter' refers to twin \#2) fit all the available semantic evidence. $R$ ather it is that neither does. The evidence does not, admittedly, allow us to choose between the two, but this is because it determines that neither alternative is empirically adequate.

${ }^{41} \mathrm{~F}$ or instance, the pragmatist slogan that truth is "the opinion which is fated to be ultimately agreed to by all who investigate" (Peirce, 1878, p. 273) has often been criticized for lapsing into either falsity or emptiness once the notion of the opinion "fated to be agreed upon" is probed further. N evertheless, a substantive, yet plausible reading of Peirce's maxim can be given in light of the considerations above. $\mathrm{N}$ amely, if the meanings of our terms become settled through the process of inquiry, then one could plausibly say that until the 'end of inquiry' the truth-values of many sentences will remain unsettled. Furthermore, since our present usage does not completely determine what the end of inquiry will be, the claim is 
a substantive one. On different histories, inquiry will reach different ends and claims such as, "Grant's zebra has striped feet," will turn out to have different truth-values. F or a discussion of this with respect to William J ames' account of intentionality and truth see J ackman, 1998b.

${ }^{42} \mathrm{~F}$ or instance, the $\mathrm{T}$-externalist can claim that our linguistic ancestors in M esopotamia referred to gold by their term corresponding to 'gold' neither (pace K ripke, 1972, Putnam, 1981) because they had unrealistically scientific "referential intentions", nor (pace Lewis, 1983) because gold is an "elite property," but rather because the comparative underdetermination of their practice allows our own developments of it to be applied retroactively. Consequently, the $\mathrm{T}$-externalist need not claim that, had they developed their term so that it turned out to be a 'functional' rather than 'natural' kind, they would have somehow lost touch with what they originally meant.

\section{REFERENCES}

A ristotle (1985). The N ichomachean Ethics, (trans. Irwin) Indianapolis: H ackett.

Belnap, N. and M. Green (1994). "Indeterminism and the Thin R ed Line", in. Tomberlin

(ed.) P hilosophical Perspectives, 8: L ogic and L anguage. A tascadero: R idgeview, pp. 365-88.

Brandom, R. (1989). T welve L ectures on $\mathrm{H}$ egel. ms, U niversity of Pittsburgh.

Burge, T. (1979). "Individualism and the M ental," in French, U ehling and Wettstein, $M$ idwest Studies in Philosophy IV: Studies in M etaphysics, M inneapolis: U niversity of M innesota Press, pp. 73-121.

Burge, T. (1988). "Individualism and Self-K nowledge", The J ournal of P hilosophy, LXXXV, pp. 649-63.

Camp, J. (1987). "W hy attributions of aboutness report soft facts", P hilosophical T opics, 15.

Davidson, D. (1987). "K nowing One's Own M ind," Proceedings and Addresses of the A merican Philosophical A ssociation, pp. 441-58.

D workin, R . (1977). Taking Rights Seriously. Cambridge, M A : H arvard U niversity Press.

Evans. G. (1973). "The Causal Theory of Names" in G. Evans (1985) Collected Papers.

N ew Y ork: Oxford U niversity Press, pp. 1-24.

Evans, G. (1982). The V arieties of R eference. N ew Y ork: Oxford U niversity Press.

Field, H. (1973). "Theory Change and the Indeterminacy of R eference," The J ournal of Philosophy, LXX, pp. 462-481.

Field, H. (1974). "Quine and the Correspondence Theory," The Philosophical Review, 83, pp. 200-28.

Gould, S. J. (1983). "What, If anything, Is a Zebra?," in S. J. Gould, Hen's Teeth and Horse's Toes, N ew Y ork: N orton, pp. 355-65.

Jackman, (1996). Semantic Norms and Temporal Externalism, PhD Thesis, U niversity of Pittsburgh.

J ackman, (1998a). "Individualism and Interpretation," Southwest P hilosophy R eview, 14(1), pp. 31-8.

Jackman, (1998b). "James' Pragmatic A ccount of Intentionality and Truth," Transactions of the C. S. Peirce Society, XXXIV(1), pp. 155-81.

K oethe, J. (1982). "The Stability of R eference Over Time," N ous, 16(2), pp. 243-52

K oethe, J. (1992). "And They A in't Outside the Head Either," Synthese, 90, pp. 27-53.

K ripke, S. (1972). N aming and N ecessity. Cambridge, M A : H arvard U niversity Press.

Lewis, D. (1983). "New Work for a Theory of U niversals," Australasian J ournal of Philosophy, 61(4), pp. 343-377.

M CG inn, C. (1982). "The Structure of Content", in Woodfield (ed.). Thought and Object, N ew Y ork: Oxford U niversity Press, pp. 207-58.

M isak, C. J. (1995). Verificationism, Its H istory and Prospects. N ew Y ork: R outledge. 
Peirce, C. S. (1878). "H ow to M ake our I deas Clear", in (1986) W ritings of Charles S. P eirce, V olume 3: 1872-1878, Bloomington: Indiana U niversity Press, pp. 257-76.

Prior, A . (1967). Past, Present and Future. Oxford: Oxford U niversity Press.

Putnam, H. (1975). "The M eaning of 'M eaning'," reprinted in his $M$ ind $L$ anguage and R eality. N ew Y ork: Cambridge U niversity Press, pp. 215-71.

Putnam, H . (1981). "W hy there isn't a ready-made world", R eprinted in H. Putnam R ealism and R eason. N ew Y ork: Cambridge U niversity Press, pp. 205-28.

Quine, W. V. O. (1960). W ord and Object. Cambridge, M A: The M IT Press.

Stich, S. (1983). From Folk P sychology to Cognitive Science. Cambridge, M A : M IT Press.

Thomason, R. (1984). "Combinations of Tense and M odality", in $\mathrm{H}$ andbook of P hilosophical L ogic, II, D ordrecht: R eidel, pp. 135-65.

Wilson, M . (1982). "Predicate M eets Property," The P hilosophical R eview, 91(4), pp. 549-89. 